\title{
Bridging the gap between doctors and nurses
}

\author{
Katrina Anne McKay', Seshasayee Narasimhan ${ }^{2}$ \\ 1. Faculty of Nursing, University of Alberta, Edmonton, Canada. 2. Mazankowski Alberta Heart Institute, Department of \\ Medicine, Cardiovascular Division, Faculty of Medicine \& Dentistry, University of Alberta, Canada. \\ Correspondence: Katrina Anne McKay. Address: Faculty of Nursing, University of Alberta, 5-112F Clinical Sciences \\ Building, 8440112 Street, Edmonton, AB T6G 2B7. E-mail: treen78@gmail.com
}

Received: January 3, 2012

DOI : $10.5430 /$ jnep.v2n4p52
Accepted: January 31, $2012 \quad$ Published: November 1, 2012

URL: http://dx.doi.org/10.5430/jnep.v2n4p52

\section{Abstract}

Nursing, throughout the ages, has crawled out of the metaphorical gutter and into the professional arena. This occurred through various efforts, including the introduction of nursing education, to professionalise nursing. The role of doctors and nurses are inherently different, which transfers to their education and professional responsibilities, respectively. These differences have led to negative stereotypes of each profession and have been seen to disrupt communication in the workplace and the confusion of each other's roles.

\section{Key words}

Doctors, Nurses, Relationships, Roles and responsibilities

\section{Background}

Throughout history, doctors and nurses have shared a complicated relationship, one that was often influenced by social status, gender, power and perspectives ${ }^{[1]}$. Quite possibly, doctors' opinion of nurses could have been influenced by the status of nurses during the pre-Nightingale era as nurses, during this time were not afforded a wonderful reputation. Nursing was considered to be 'arduous and ill-paid', attracting people who were regarded to be unfit for other occupations ${ }^{[2]}$. These people included criminals, vagrants, and immoral women ${ }^{[2-4]}$. Nightingale's efforts have been well documented, as she was a catalyst for systematic inquiry.

Nursing went through a process of professionalisation, where the role and status of nursing was redefined and formal university qualifications were introduced ${ }^{[5]}$. However, throughout the 1970-80s, doctors continued to hold an omnipotent and undisputed position in the clinical arena ${ }^{[6]}$. This has been described as the doctor/nurse game, referring to the relationships of power between doctors and nurses. The traditional relationship was a simple hierarchy, where doctors were superior to nurses ${ }^{[5]}$. Additionally, doctors dominated medical science by advantage of social position and a monopoly of knowledge ${ }^{[6]}$. Continuing into the 1990s, the relationship between doctors and nurses appeared to patients to support the idea of worshipping medical sciences and to emphasize the status and importance of doctors. Nursing skills and training were devalued in the clinical setting, where nurses were expected to remain quiet and ensure that ward rounds functioned smoothly and efficiently ${ }^{[6,7]}$. However, it was noted that in 1990, the doctor/nurse game had changed. Nurses challenged doctors, offered advice and were regarded with more respect ${ }^{[5]}$. 
During the Victorian era, society's view of women and their 'proper place' in it, greatly influenced nursing as a profession ${ }^{[2]}$. Since the introduction of nursing schools, nurses received a new level of respect from the public and it was the beginning of evolution from a vocation to profession ${ }^{[3]}$. However, in 2007, Hebert described the public perception of doctors as being a group of people who are admired for being elitist, wealthy, intelligent, and powerful ${ }^{[4]}$. However, nurses are seen as inferior and being apart of the working-class. This is further supported by the classification of social class based on occupation (see Table 1$)^{[8]}$. This leads to ask the question, what is it that continues to separate doctors and nurses professionally?

Table 1. Social class based on occupation ${ }^{[8]}$

\begin{tabular}{ll}
\hline Social class & Occupation \\
\hline I Professional & Accountants, engineers, doctors \\
II Managerial and technical/intermediate & Nurses, marketing and sales managers, teachers, journalists \\
III Non-manual skilled & Clerks, shop-assistants and cashiers \\
IV Partly skilled & Security guards, machine tool operators, farm workers \\
V Unskilled & Building and civil engineer labourers, other labourers, cleaners \\
\hline
\end{tabular}

\section{Education}

There are two key components that separate doctors and nurses professionally: education and professional responsibilities. A brief overview of the two degrees, based in an Australian University (Bachelor of Medicine/ Bachelor of Surgery (MBBS) and Bachelor of Nursing) identifies that MBBS requires pre-requisites of 4 semesters with a sound achievement of English and Mathematics B ${ }^{[9]}$, and 1 semester of biology, chemistry or physics ${ }^{[10]}$. Two years of undergraduate medical science must be completed before commencing the 4-year, theoretically and clinically comprehensive MBBS degree. This does not include the postgraduate years to continue to learn and train to become specialists. Nursing, however, only requires pre-requisites of 4 semesters with a sound achievement of English ${ }^{[10]}$ and a 3-year degree. Though the nursing curriculum covers a variety of topics, it does not prepare the individual for real world nursing including familiarity with hospital systems, communication with doctors, and most importantly the steep learning curve of clinical nursing.

Though expecting registered nurses (RN) to be diagnosticians as a part of their clinical role is laudable, without the same level of education and training like a physician, this is impossible to achieve. In reality, it would require nursing assessment to be clinically based as opposed to the current task-oriented approach. To help address this issue, the existing curriculum for RN's need significant modification

\section{Roles and responsibilities}

Despite the social and professional view that nurses are second rate to doctors, there is a vast difference between the two professions. The essence of each are different, yet are required to achieve the same goal. The role of nursing, simply put, is to care and that of a doctor is to cure. Neither is mutually exclusive, in fact one cannot successfully function without the other. Therefore, professional responsibility differs. Unfortunately, there seems to be discordance between doctors and nurses with respect to their roles and responsibilities (see Table 2) ${ }^{[11,12]}$.

There is published literature which focused on communication in the operating room and found that the most notable themes to affect communication 'were confused and conflicting role perceptions' ${ }^{[13]}$. It is interesting to note that in the 1980's doctors held a monopoly on knowledge, yet were concerned with the levels of competence of nurses. It has been reported that doctors believed that nurses wanted authority, but were not properly trained. Furthermore, they felt that 
nurses 'make noises about inconsequential things, and ignore data they should be informing you about', and 'good nurses end up behind desks as administrators' ${ }^{[14]}$. Given the lack of preparation for real world nursing, a nursing graduate working on the wards could easily assume that the doctor would be available at any time to respond to queries and requests. This could certainly lead to difficult interactions thereby 'widening the gap'.

Table 2. Roles and Responsibilites ${ }^{[11,12]}$

\begin{tabular}{|c|c|}
\hline Role of the doctor ${ }^{[11]}$ & Role of a nurse $^{[12]}$ \\
\hline $\begin{array}{l}\text { 1. Provide and maintain a trusting relationship with } \\
\text { their patients }\end{array}$ & $\begin{array}{l}\text { 1. Practice in accordance with legislation affecting nursing practice and } \\
\text { health care }\end{array}$ \\
\hline $\begin{array}{l}\text { 2. Respond to the initial presentation of illness and } \\
\text { provide a diagnosis and prognosis for the patient }\end{array}$ & 2. Practice within a professional and ethical nursing framework \\
\hline 3. Complex decision making & 3. Practice within an evidence-based framework \\
\hline $\begin{array}{l}\text { 4. Use a multidisciplinary approach, providing } \\
\text { leadership and being ultimately responsible for the care } \\
\text { of the patient }\end{array}$ & 4. Participate in ongoing professional development of self and others \\
\hline $\begin{array}{l}\text { 5. Being professional by maintaining high personal } \\
\text { ethical standards }\end{array}$ & 5. Conduct a comprehensive and systematic nursing assessment \\
\hline $\begin{array}{l}\text { 6. Providing leadership and management in health } \\
\text { service management and organizations }\end{array}$ & $\begin{array}{l}\text { 6. Plan nursing care in consultation with individuals/groups, significant } \\
\text { others and the interdisciplinary health care team }\end{array}$ \\
\hline \multirow[t]{4}{*}{ 7. Training of current and future generations } & $\begin{array}{l}\text { 7. Provide comprehensive, safe and effective evidence-based nursing care } \\
\text { to achieve identified individual/group health outcomes }\end{array}$ \\
\hline & $\begin{array}{l}\text { 8. Evaluate progress towards expected individual/group health outcomes } \\
\text { in consultation with individuals/groups, significant others and } \\
\text { interdisciplinary health care team }\end{array}$ \\
\hline & $\begin{array}{l}\text { 9. Establish, maintain and appropriately conclude therapeutic } \\
\text { relationships }\end{array}$ \\
\hline & $\begin{array}{l}\text { 10. Collaborate with the interdisciplinary health care team to provide } \\
\text { comprehensive nursing care }\end{array}$ \\
\hline
\end{tabular}

\section{Solution}

To bridge the gap and improve both educational and role perception deficits, it could be argued that there is a need for inter-professional education. It is believed that to change inter-professional relationships, shared learning could be introduced at the undergraduate level ${ }^{[3,7]}$. Inter-professional education programmes should encourage 'mutual intergroup differentiation' to promote positive attitude change through acknowledgement of each group's valued identity on specific dimensions ${ }^{[7]}$. This could achieve the reduction of negative stereotypes and provide a 'synergistic approach to the patient ${ }^{\text {' }}{ }^{4]}$. Additionally, combined education, may improve nursing curriculum, so that RN's can utilize greater clinical thinking when assessing patients. 


\section{Conclusion}

There has been significant change throughout the history of nursing; from the introduction of nursing schools, hospital based apprenticeship training, university education to nursing unions. As nursing science advanced, so did the responsibility to learn more and be more involved in clinical patient care ${ }^{[3]}$. Despite the efforts to professionalise nursing, it is still seen, socially and professionally, as inferior in some cultures. The educational pre-requisites certainly reflect a difference in ability and could be seen as lesser than. However, the two roles of doctor and nurse are inherently different, therefore the educational requirements should not be dissimilar. It is vital to remember that despite these differences, both professions are inter-dependent to provide optimal patient care, which is the ultimate goal. Unfortunately, professional differences are not embraced by both groups and are instead used to create negative stereotypes and leads to confusion of each other's roles and responsibilities. To alleviate this, inter-professional education at the undergraduate level could be introduced. This could promote an understanding of each other's roles and achieve a positive attitude change and possibly a more cohesive relationship. This could, eventually, bridge the gap we seek to eliminate and enhance nurses and nursing.

\section{References}

[1] Salvage, J, Smith, R. Doctors and nurses: doing it differently. The time is ripe for a major reconstruction. BMJ. 2000; 320: 1019-20. PMid:10764342 http://dx.doi.org/10.1136/bmj.320.7241.1019

[2] Hein, E. Nursing Issues in the 21st Century: Perspectives from the Literature. Lippincott, USA. 2001; 59-61.

[3] Greenfield, L. Doctors and Nurses: A Troubled Partnership. Annals of Surgery. 1999; 230(3): 279-288. PMid:10493475 http://dx.doi.org/10.1097/00000658-199909000-00001

[4] Hebert, E. The Difference between Doctors and Nurses [Internet]. 2007. Available from: http://www.rncentral.com/nursing-library/the-difference-between

[5] Germov, J, Freij, M. The Doctor/Nurse Game. Second Opinion, 4. 2009. Available from: http://www.oup.com.au/titles/higher_ed/social_science/sociology/9780195562811/Ch20_Case_Study_-_Doctor-Nurse_ Game.pdf

[6] Svensson, R. The interplay between doctors and nurses - a negotiated order perspective. Sociology of Health \& Illness. 1996; 18(3): 379-398. http://dx.doi.org/10.1111/1467-9566.ep10934735

[7] Carpenter, J. Doctors and nurses: stereotype and stereotype change in professional education. Journal of Interprofessional Care. 1995; 9(2): 151-161.

[8] Peate, I. Becoming a Nurse in the 21st Century. John Wiley \& Sons Ltd. 2006; 102.

[9] Queensland Studies Authority. Mathematics B Senior Syllabus [Internet]. 2008. Available from: http://www.qsa.qld.edu.au/downloads/senior/snr_maths_b_08_syll.pdf

[10] Queensland Tertiary Admissions Centre. Student Advisers’ Tertiary Course List [Internet]. 2001; 19. Available from: http://www.qtac.edu.au/Downloads/Schools/SATCL_5_Dec_2011.pdf

[11] Australian Medical Association. Role of the doctor [Internet]. 2011. Available from: http://ama.com.au/node/6569

[12] Australian Nursing Federation. Competency Standards for nurses in general practice [Internet]. 2006. Available from: http://www.anf.org.au/nurses_gp/resource_03.pdf

[13] Nestel, D, Kidd, J. Nurses’ perceptions and experiences of communication in the operating theatre: a focus group interview. BMC Nursing [Internet]. 2006; 5:1. Available from: http://www.biomedcentral.com/1472-6955/5/1. PMid:16466581 http://dx.doi.org/10.1186/1472-6955-5-1

[14] Reichman, S. Conflicts and Collaboration: Nurse-Physician Issues In The Hospital*. Bull. N.Y. Acad. Med. 1984; 60(8): 819-824. PMid:6594175 